\title{
A direct assay to assess self-grooming behavior in honey bees (Apis mellifera L.)
}

\author{
Nuria Morfin ${ }^{1}$, Laura G. Espinosa-MonTAÑo ${ }^{2}$, Ernesto GuZMAn-NovoA ${ }^{1}$ \\ ${ }^{1}$ School of Environmental Sciences, University of Guelph, 50 Stone Road East, Guelph, Ontario N1G 2W1, Canada \\ ${ }^{2}$ Departamento de Medicina y Zootecnia de Abejas, FMVZ, UNAM. Cd. University, 04510, Mexico City, Mexico
}

Received 15 June 2019 - Revised 5 March 2020 - Accepted 7 April 2020

\begin{abstract}
Grooming behavior confers resistance to honey bees against the mite Varroa destructor and thus is a mechanism of interest for studies of social immunity and breeding purposes. However, mites are not always available to conduct grooming assays and can introduce variability to the evaluations. Therefore, the objective of this study was to evaluate the use of wheat flour as an irritant in a laboratory assay to assess self-grooming behavior in honey bees. Presumed Varroa -susceptible and Varroa-resistant genotypes were used to determine the time it took the bees to initiate grooming instances and the proportion of bees that responded when exposed to either flour or a Varroa mite. Flour elicited significantly faster grooming responses and with a higher proportion of individuals in both genotypes in comparison with $V$. destructor. Also, significant differences between both genotypes were observed. It is concluded that flour can be used as an irritant instead of $V$. destructor to evaluate self-grooming behavior in bees in the laboratory.
\end{abstract}

\section{honey bees / grooming behavior / varroa destructor / bioassay}

\section{INTRODUCTION}

Varroa destructor is the most damaging parasite of honey bees. It has been found to be associated with high rates of colony mortality (GuzmanNovoa et al. 2010; Le Conte et al. 2010). Honey bees have developed defense mechanisms against parasitic mites like $V$. destructor, including grooming behavior, which consists in the use of legs and mandibles, as well as abdomen shaking to attempt to remove mites from their bodies (Peng et al. 1987).

Grooming behavior can restrain the growth of $V$. destructor populations in honey bee colonies (Arechavaleta-Velasco and Guzman-Novoa

Corresponding author: N. Morfin, nmorfinr@uoguelph.ca

Manuscript editor: Yves Le Conte
2001). In fact, several studies have shown that certain bee genotypes such as the so-called Africanized bees (hybrids of Apis mellifera scutellata) are more resistant than European bees to $V$. destructor, in part due to differences in grooming behavior (Moretto et al. 1993; Guzman-Novoa et al. 1999; Aumeier 2001; Invernizzi et al. 2015). Clearly, grooming behavior is a mechanism of interest for studies of social immunity and breeding purposes. However, the assessment of grooming behavior is challenging. Indirect methods of assessing this behavior are based on counting the number of fallen and mutilated mites on sticky papers placed on the bottom boards of hives (Ruttner and Hänel 1992). However, these methods do not solely measure the effects of grooming behavior. Mites can fall and show body mutilations due to several other factors (Boecking and Spivak 1999). Thus, more reliable methods of measuring the behavior are needed for studies that require more precision. 
Direct observation of grooming instances by bees can substantially reduce the unreliable nature of indirect methods. Direct methods of assessing the behavior include the visualization of bees grooming their bodies for a period of time when artificially infested with Varroa mites in observation hives (Peng et al. 1987; Fries et al. 1996) or in a Petri dish (Aumeier 2001). Molecular markers have been found to be associated with individual grooming behavior (Arechavaleta-Velasco et al. 2012). For example, Neurexin has been found to be overexpressed in bees that self-groom intensively (Hamiduzzaman et al. 2017), which validates the use of individual laboratory assays to assess self-grooming in bees. However, these methods depend on the availability of $V$. destructor mites at different times of the year. Moreover, $V$. destructor could also introduce variability in the evaluation of the behavior due to differences in their ability to get attached to the bee, as some could be damaged during the collection procedure as has been observed by the authors. Therefore, an assay to assess individual grooming behavior with an irritant that is not a $V$. destructor mite may be of aid to evaluate selfgrooming behavior at different times of the year in a consistent manner.

The objective of this study was to evaluate the use of wheat flour as an irritant to assess selfgrooming behavior in honey bees instead of using V. destructor mites. Presumed Varroa -susceptible and Varroa -resistant genotypes (Carniolan and Africanized bees, respectively) were used to determine the time it took the bees to initiate grooming instances and the proportion of bees that responded when exposed to either flour or a V. destructor mite.

\section{MATERIALS AND METHODS}

\subsection{Source of honey bees and $V$. destructor}

The worker bees used in this study were obtained from Africanized and European (Carniolan) bee colonies kept at the Honey Bee Breeding and Beekeeping Technology Centre of Mexico's Institute of Forestry, Agriculture and Livestock Research (INIFAP), in Villa Guerrero, Mexico $\left(18^{\circ} 57^{\prime} \mathrm{N}, 99^{\circ} 38^{\prime} \mathrm{W}\right)$.
The source of Africanized bees included colonies previously used by Guzman-Novoa et al. (2012), which demonstrated significant increases in grooming behavior, mite removal success, and lower colony mite rates than colonies of European bee populations. The daily mite fall rates (on sticky papers) of the experimental colonies used differed significantly $\left(t_{4}=5.1, p<0.01\right)$ and were $45.7 \pm 5.6$ and $14.7 \pm 2.4$ mites for the European and Africanized bee colonies, respectively. The genotype of the colonies was confirmed by morphometric and mt DNA analyses of their bees (Nielsen et al. 1999). V. destructor mites were collected from heavily infested colonies as per Arechavaleta-Velasco and Guzman-Novoa (2001). Those colonies were different from the ones used to collect honey bees.

\subsection{Self-grooming behavior trials}

Adult honey bees were collected from the center of the brood chamber of the experimental colonies used in the self-grooming trials. Individual trials of grooming behavior were carried out in a laboratory at room temperature as described by Aumeier (2001) with modifications as per Guzman-Novoa et al. (2012). Briefly, each bee was gently placed inside a sterile Petri dish $(100 \mathrm{~mm} \times 15 \mathrm{~mm}$, FisherScientific $®$ Mississauga, ON, Canada) that was prepared in advance by lining its bottom with a circular piece of Whatman $^{\mathrm{TM}}$ white filter paper (FisherScientific, Mississauga, ON, Canada) and covering it with plastic wrap, which was perforated 20-30 times with a nail $(50 \times 3 \mathrm{~mm})$. Twenty milligram of wheat flour (Tres Estrellas $®$, Toluca, Mex, Mexico) per bee was measured in a scale (Denver Instrument ${ }^{\circledR}$, Bohemia, NY, USA) before starting the self-grooming trials. Once the bee was introduced into the Petri dish, she was left for 2 min to become accustomed to the environment. Then, the plastic wrap cover was slightly lifted to place the wheat flour or one $V$. destructor mite on the thorax of each bee with a flat fine paintbrush (6 $\mathrm{mm} \times 11 \mathrm{~mm}$, DeSerres ${ }^{\circledR}$, Oakville, ON, Canada). Each mite was used for one behavioral assay to avoid reusing mites that could have been injured by the self-grooming behavior of the bees, 
thus affecting the results. For the control groups, Africanized or European bees were touched on the thorax with the bristles of a paintbrush of the same type as that used to apply the flour or the mites on the bees. The purpose of the control groups was to assess the effect of the touch by the paintbrush on the bees, which could result in grooming instances.

A stopwatch was started immediately after the application of the irritant, or the touch, and the bee was observed for $5 \mathrm{~min}$. The time of first grooming response (movements of legs over the head, thorax or abdomen) was recorded. The proportion of bees that groomed at $\leq 60 \mathrm{~s}$ after exposure to an irritant or paintbrush touch was also determined. Bees of Varroa-susceptible and Varroa-resistant genotypes have consistently and significantly shown differences for these variables in previous studies (Aumeier 2001; ArechavaletaVelasco et al. 2012; Guzman-Novoa et al. 2012). There was only one observer of grooming trials, which were conducted with 161 Africanized and 157 European bees.

\subsection{Statistical analysis}

(To compare treatments for time to react to the irritants or paintbrush touch by self-grooming, the data were subjected to a Kruskal-Wallis test and multiple pairwise comparisons using the Conover-Iman procedure ( $\alpha$ of 0.05 ), as they did not comply with normality based on a Shapiro Wilk test. To compare treatments for proportions of bees that groomed at $\leq 60 \mathrm{~s}$, contingency tables with chi-squared tests of independence ( $\alpha$ of 0.05 ) were used, and adjusted residuals were calculated for post hoc analyses. The analyses were done with R version 3.4.3@ (the R Foundation for Statistical Computing, 2017) and XLSTAT ( (2019).

\section{RESULTS}

Significant differences were found between treatments for time to react to the irritants by self-grooming $\left(\chi^{2}=56.03, p<0.0001\right.$; Figure 1). Africanized bees reacted significantly faster than the control and European bees to flour $(26.85 \pm 2 \mathrm{~s})$ and $V$. destructor (59.52 $\pm 7.3 \mathrm{~s})$.

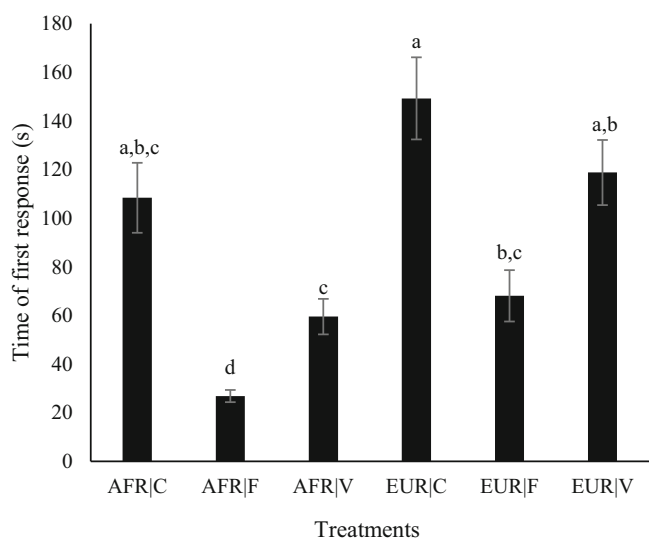

Figure 1. Mean time of first grooming response to an irritant ( \pm S.E.), a $V$. destructor mite $(\mathrm{V})$ or $20 \mathrm{mg}$ of wheat flour $(\mathrm{F})$, or to a paint brush touch for the control groups (C) in bees of Africanized (AFR) and European (EUR) genotypes $(N=318)$. Different letters above bars indicate significant differences using a KruskalWallis test and Conover-Iman procedure ( $\alpha$ of 0.05 ). Non-transformed data are presented

European bees reacted to flour in $68.08 \pm 10.56 \mathrm{~s}$ and to $V$. destructor in $118.77 \pm 13.4 \mathrm{~s}$. European bees started grooming themselves significantly faster than the control when exposed to flour, but not when exposed to $V$. destructor. Thus, flour elicited a significantly faster response, compared with $V$. destructor and the control in both Africanized and European bees $\left(\chi^{2}=28.31, p<\right.$ $0.0001 ; \chi^{2}=12.63, p<0.002$, respectively). No differences were found between the two genotype control treatments for time to start grooming $(p>$ $0.05)$.

A significantly higher proportion of Africanized bees groomed at $\leq 60 \mathrm{~s}$ as a response to flour (0.94), compared with $V$. destructor $(0.56)$ and the control $(0.45)\left(\chi^{2}=31.85, p<\right.$ 0.0001 ; Table I). Also, a significantly higher proportion of European bees groomed with flour $(0.64)\left(\chi^{2}=11.07, p=0.004\right)$, compared with the proportion of European bees that groomed with $V$. destructor $(0.34)$ or the control (0.39). Lastly, a significantly higher proportion of Africanized bees responded to flour by self-grooming compared with European bees $\left(\chi^{2}=41.38, p<0.0001\right)$. 
Table I.. Number and proportion of bees of Africanized and European genotype that groomed at $\leq 60 \mathrm{~s}$ after exposure to either a $V$. destructor mite, $20 \mathrm{mg}$ of wheat flour, or a touch of a paintbrush (as control)

\begin{tabular}{llcc}
\hline Treatment & $N$ & Number bees that groomed at $\leq 60 \mathrm{~s}$ & Proportion of groomers \\
\hline Africanized control & 55 & 25 & 0.45 \\
Africanized + flour & 54 & 51 & $0.94 *$ \\
Africanized + V. destructor & 52 & 29 & 0.56 \\
European control & 51 & 20 & 0.39 \\
European + flour & 53 & 34 & $0.64 *$ \\
European + V. destructor & 53 & 18 & 0.34 \\
\hline
\end{tabular}

Asterisks indicate a significant increase in the proportion of bees that self-groomed based on chi-squared tests and adjusted residuals $(p=0.0083)$ compared with the respective controls

\section{DISCUSSION}

The individual self-grooming assay described by Aumeier (2001) has been proven effective to identify differences in grooming behavior of different honey bee genotypes by evaluating various components of the behavior, including time of first response and the proportion of bees responding after being exposed to a $V$. destructor mite. The results of this study agree with those of Aumeier (2001) because Africanized bees groomed themselves faster and responded with a higher proportion of individuals to the irritation caused by $V$. destructor than European bees. But more importantly, when bees were exposed to flour, both genotypes initiated grooming instances significantly faster than bees exposed to $V$. destructor or the controls. Aumeier (2001) also reported differences for the intensity of self-grooming behavior between Africanized and Carniolan bees; thus, further studies on the differences in grooming intensity using flour as an irritant between tolerant and susceptible genotypes of bees to $V$. destructor parasitism would be of value to provide more information on the use of flour in individual grooming assays. Also, the effect of different quantities of flour or other irritants should be tested in future studies. Moreover, the potential impact of seasonal effects on selfgrooming behavior should be taken into consideration to further investigate other variables influencing grooming behavior.

In addition to the above, a significantly higher proportion of both European and Africanized bees reacted to flour at $\leq 60 \mathrm{~s}$ after its application compared with the control and the $V$. destructor treatments. Clearly, flour was the irritant that caused a faster response and with a higher number of individuals in both bee types, demonstrating that flour was able to provoke a self-grooming response consistently regardless of bee genotype. Additionally, significant differences between the two genotypes used were found for the two variables measured, which indicates that the use of flour can separate genotypes by level of grooming response. Moreover, no significant differences were found between the time of first response to $V$. destructor and the control in European bees, but a significantly faster reaction was observed with flour. Although flour could be a more effective irritant to assess selfgrooming behavior, particularly in European bees, the results of this study should be taken cautiously, as the faster response with flour compared with $V$. destructor could overestimate grooming responses. Thus, the evaluation of more than one variable linked to grooming behavior, such as the proportion of bees that groomed, or the intensity of grooming, should be analyzed jointly with the time of reaction, to have a more comprehensive evaluation of grooming behavior. Also, to the best of our knowledge, there are no studies reporting on differences in the neural processes related to the perception of a $V$. destructor mite, pollen, or other particles on the bee's body that could elicit different grooming responses related to the type of irritant. The aim of this study was not to validate the use of the individual grooming assay with flour as the only 
assay to evaluate resistance to $V$. destructor but to have an alternative to the self-grooming trial instead of using a $V$. destructor mite. Thus, the evaluation of $V$. destructor resistance through traits associated with grooming behavior in honey bees should be done using a comprehensive approach. Additional evaluations, such as mite population growth in colonies or proportion of mutilated mites (Morfin et al. 2020), could be used as a complement to the selfgrooming assays.

Besides providing consistent results, another advantage of using flour as an irritant to evaluate grooming behavior in individual honey bees is that researchers would not be limited by the seasonal availability of viable $V$. destructor mites to perform the assay. Furthermore, flour could be used to evaluate grooming behavior associated to the resistance of honey bees to other parasites such as Acarapis woodi, as Danka and Villa (2003) noted that a higher proportion of bees that self-groomed were resistant to the tracheal mite. Also, the proposed assay could be used to assess the effect of stressors that could potentially affect self-grooming behavior, such as neurotoxins (Morfin et al. 2019). In conclusion, flour can be used as an irritant instead of $V$. destructor to evaluate self-grooming behavior in bees in the laboratory.

\section{AUTHORS CONTRIBUTIONS}

EG project planning and design; LE conducted field experiments; NM, EG, and LE analyzed the data; and NM and EG wrote the paper. All authors read and approved the final manuscript.

\section{FUNDING INFORMATION}

This study was funded by Mexico's Institute of Forestry, Agriculture and Livestock Research (INIFAP grant no. 22329) and the Technology Innovation and Research Program of the National University of Mexico (grant no. IN222203).

\section{DATA AVAILABILITY}

The dataset of the current study is available from the corresponding author on reasonable request.

\section{COM PLIA N CE WITH ETHICAL STANDARDS}

Conflict of interest The authors declare that they have no conflict of interests.

Un test direct pour évaluer le comportement d'autotoilettage des abeilles (Apis mellifera L.).

abeilles domestiques / comportement de toilettage / Varroa destructor / test biologique.

Ein direkter Test, um das Selbstgrooming-Verhalten bei Honigbienen (Apis mellifera L.) zu beurteilen. Honigbienen / Grooming-Verhalten / Varroa destructor
/ Biotest.

\section{REFERENCES}

Arechavaleta-Velasco, M. E., Guzman-Novoa, E. (2001). Relative effect of four characteristics that restrain the population growth of the mite Varroa destructor in honey bee (Apis mellifera) colonies. Apidologie, 32 (2), 157-174.

Arechavaleta-Velasco, M. E., Alcala-Escamilla, K., Robles-Rios, C., Tsuruda, J. M., Hunt, G. J. (2012). Fine-scale linkage mapping reveals a small set of candidate genes influencing honey bee grooming behavior in response to Varroa mites. PLoS One, 7 (11), e47269.

Aumeier, P. (2001). Bioassay for grooming effectiveness towards Varroa destructor mites in Africanized and Carniolan honey bees. Apidologie, 32 (1), 81-90.

Boecking, O., Spivak, M. (1999). Behavioral defenses of honey bees against Varroa jacobsoni Oud. Apidologie, 30 (2-3), 141-158.

Danka, R. G., Villa, J. D. (2003). Autogrooming by resistant honey bees challenged with individual tracheal mites. Apidologie, 34 (6), 591-596.

Fries I., Huazhen W., Wie S., Jin C. S. (1996). Grooming behavior and damaged mites (Varroa jacobsoni) in Apis cerana cerana and Apis mellifera ligustica. Apidologie, 27 (1), 3-11.

Guzman-Novoa, E., Vandame, R., Arechavaleta-Velasco, M. E. (1999). Susceptibility of European and Africanized honey bees (Apis mellifera L.) to Varroa 
jacobsoni Oud. in Mexico. Apidologie, 30 (2-3), 173182.

Guzman-Novoa, E., Eccles, L., Calvete, Y., McGowan, J., Kelly, P. G., Correa-Benítez, A. (2010). Varroa destructor is the main culprit for the death and reduced populations of overwintered honey bee (Apis mellifera ) colonies in Ontario, Canada. Apidologie, 41 (4), 443-450.

Guzman-Novoa, E., Emsen, B., Unger, P., EspinosaMontaño, L. G., Petukhova, T. (2012). Genotypic variability and relationships between mite infestation levels, mite damage, grooming intensity, and removal of Varroa destructor mites in selected strains of worker honey bees (Apis mellifera L.). J. Invertebr. Pathol., 110 (3), 314-320.

Hamiduzzaman, M. M., Emsen, B., Hunt, G. J., Subramanyam, S., Williams, C. E., Tsuruda, J. M., Guzman-Novoa, E. (2017). Differential gene expression associated with honey bee grooming behavior in response to Varroa mites. Behav. Genet. , 47 (3), 335-344.

Invernizzi, C., Zefferino, I., Santos, E., Sánchez, L., Mendoza, Y. (2015). Multilevel assessment of grooming behavior against Varroa destructor in Italian and Africanized honey bees. J. Apicult. Res., 54 (4), 321-327.

Le Conte, Y., Ellis, M., Ritter, W. (2010). Varroa mites and honey bee health: can Varroa explain part of the colony losses? Apidologie, 41 (3), 353-363.

Moretto, G., Gonçalves, L. S., De Jong, D. (1993). Heritability of Africanized and European honey bee defensive behavior against the mite Varroa jacobsoni . Revista Brasileira de Genetica, 16, 71-71.

Morfin, N., Goodwin, P. H., Hunt, G. J., Guzman-Novoa, E. (2019). Effects of sublethal doses of clothianidin and/or $V$. destructor on honey bee (Apis mellifera) self-grooming behavior and associated gene expression. Scientific Reports, 9 (1), 5196.

Morfin, N., Given, K., Evans, M., Guzman-Novoa, E., Hunt J.G. (2020) Grooming behavior and gene expression of the Indiana "mite-biter" honey bee stock. Apidologie.

Nielsen, D. I., Ebert, P. R., Hunt, G. J., Guzmán-Novoa, E., Kinnee, S. A., Page Jr, R. E. (1999). Identification of Africanized honey bees (Hymenoptera: Apidae) incorporating morphometrics and an improved polymerase chain reaction mitotyping procedure. Ann. Entomol. Soc. Am., 92 (2), 167-174.

Peng, Y., Fang, Y., Xu, S., Ge, L. (1987). The resistance mechanism of the Asian honey bee, Apis cerana Fabr. to an ectoparasitic mite, Varroa jacobsoni Oudemans. J. Invertebr. Pathol., 49(1), 54-60.

Ruttner, F., Hänel, H. (1992). Active defense against Varroa mites in a Carniolan strain of honeybee (Apis mellifera carnica Pollmann). Apidologie, 23 (2), 173-187.

Publisher's note Springer Nature remains neutral with regard to jurisdictional claims in published maps and institutional affiliations. 